\title{
Collective responsibilities
}

\section{China should stop discouraging scientists from setting up learned societies.}

T he spread in China of unproven stem-cell therapies for conditions such as epilepsy and spinal cord injuries has left the nation's health authorities concerned. There is no clear evidence that these treatments work - nor that they are killing people. Of the thousands of patients from China and abroad who have been treated, some seem to think that they have been helped, even if only modestly, and many more are ready to fork out thousands or tens of thousands of dollars to try out the treatments. Are the clinicians taking advantage of people desperate for a cure? How can the government - and the potential patients - make sense of this?

One obvious place from which to seek guidance would be the national stem-cell society. But China doesn't have one. A group of scientists, including many of the country's most prominent and internationally established researchers, are trying to create one.

The Chinese authorities, however, tend to have an aversion to congregations - especially those such as the Falun Gong, which they believe pose a threat to the country's stability. So the Ministry of Civil Affairs keeps a tight hold on who is allowed to organize in any formal sense. As a result, China's stem-cell hopefuls must go through the slow process of planning and applying to become a 'level 2' society. That means they have to convince an established society to take them on as an appendage, which will dramatically reduce their ability to function effectively. A level 2 society doesn't control its own purse strings and decisions have to pass through the parent organization.

Yet, as the example above illustrates, allowing scientists to draw together can only benefit China, both by helping scientific progress and by assisting with the challenges faced by the Chinese nation.

It is not just the government that needs to rethink its approach: the researchers themselves need to pursue newer forms of social organization. Scientists in the south often don't know what is happening in the north and vice versa. Most of the current learned societies do not function well. Annual meetings are often a matter of pomp, with elite researchers showing up to swagger about and form cliques based on pedigree rather than scientific views. Introducing graduate students to the broader community is a low priority. Constructive criticism is more likely be taken as grounds for breaking off relations than as insightful advice. Many scientists simply don't bother to go.

Sometimes 'megaprojects' draw researchers together. But the planning meetings for
"Scientists in the south of China often don't know in the north and vice versa." what is happening such packages can be more like dividing the spoils than building the most constructive research programme.

China's science loses competitiveness because of these failings. Stronger societies would pave the way for better communication and more productive collaborations, and would allow a platform for feedback of scientific criticism. That, in turn, would provide a body of honest reviewers with whom funding bodies could consult. Too often, instead of listening to a variety of voices to get a representative view from 'the community', funding bodies listen only to certain well connected scientists. Strong domestic scientific societies have the additional benefit of being reference points for constructive contact with scientists and societies elsewhere. And they can also act as advisory bodies to the government.

Gone are the days of small research communities in China. Science has grown significantly, to China's credit and benefit. For the country to benefit more fully, networking by its researchers likewise needs to be allowed to flourish.

\section{Identity crisis}

\section{It is time for all involved to tackle the chronic scandal of cell-line contamination. Funders first.}

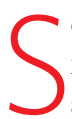
ome 40 years after it was first recognized, the use of contaminated and misidentified cell lines in biological research remains a growing problem. But it is a problem that has a simple solution: routine, cheap, DNA profiling of laboratory cultures. It is now time to implement that solution. To do so, scientists need the funding and motivation to verify the cell lines in their possession, as well as a curated electronic database of authenticated DNA profiles against which they can compare their results.

Thousands of biology labs use cell lines, yet many do not know that between a fifth and a third of the lines in common use may not be what they seem. In the past 25 years, numerous studies, as well as the experience of cell-culture repositories in the United States, Britain, Germany and Japan, have found that $18-36 \%$ of cultures contain a misidentified species or cell type. The effect of using such cells varies depending on the project involved. When the lines are used as a source of biochemicals, for example, the misidentified lines are innocuous. Deployed in the study of a general cellular process, they can have minor drawbacks. But on the rare occasions that the cell lines are thought to reflect the properties of a particular tissue, cancer or disease state, the outcome can be severely damaging as funding and research get driven into work based on false premises.

To make matters worse, papers are still published that contain unwarranted conclusions derived from misidentified lines. It is ironic that many researchers who are obsessed with using only the highestquality chemicals and biologics from the most trusted suppliers don't think twice about using cell lines known to be misidentified.

Cell repositories do carry out quality-control assays on deposited lines, although the tests performed vary. Even a venerated panel of 